\title{
Reflexões sobre filiação adotiva: avanços e desafios no Brasil e em Portugal
}

\author{
Dorian Mônica Arpini* \\ Isabel Santa Bárbara Narciso**
}

\section{Resumo}

Este artigo apresenta uma reflexão sobre a adoção, em especial sobre a forma como esta relação de filiação vem sendo construída em duas realidades distintas - Brasil e Portugal. Tem como objetivo destacar a importância da condução do processo e o papel atribuído aos técnicos na construção destes laços. Destaca algumas ações e alterações que vêm sendo desenvolvidas e que podem auxiliar na qualificação do processo de adoção e no fortalecimento das relações, como a aproximação entre candidatos e adotantes, redução do tempo de espera e apoio as famílias adotantes. Salienta que o tema vem sendo abordado com mais abertura, no entanto, ainda se encontra encoberto por muitos temores e fantasmas.

Palavras-chave: Adoção; Relações Familiares; Membros da Família; Processos Legais; Criança Institucionalizada.

\section{Reflections on adoptive filiation: advances and challenges in Brazil and in Portugal}

\section{Abstract}

This study presents a reflection on adoption, especially about the ways such filiation relationship is being carried out in two distinct realities - Brazil and Portugal. Its aim is to highlight the importance of the conduction of the process and the role attributed to technicians regarding building up such bonds. It underlines some actions that have been developed and that may help as concerns the improvement of the process and strengthening of bonds, such as the care related to bringing candidates and adopters, careful follow up of the process, reduction of waiting time and support to the adopting families. Such theme has been approached more openly, even though it is still covered by fears and fantasies.

Keywords: Adoption; Family Relations; Family Members; Legal Processes; Child Institutionalized.

* Psicóloga, Professora Associada IV do Departamento de Psicologia e do Programa de Pós-graduação em Psicologia da Universidade Federal de Santa Maria. Tutora da Residência Multiprofissional em Sistema Público de Saúde da Universidade Federal de Santa Maria.

** Psicóloga. Professora da Faculdade de Psicologia e do Programa de Pós-graduação em Psicologia da Universidade de Lisboa/Portugal. 


\section{Introdução}

Este artigo objetiva uma reflexão acerca das práticas de adoção de crianças e adolescentes tomando como referência as experiências de dois países, a saber: Brasil e Portugal. Objetivamos que o texto auxilie no conhecimento a respeito do tema e das mudanças que vêm acontecendo neste cenário. Num primeiro momento, parece importante destacar que abordar o tema da adoção é de extrema relevância no contexto dos estudos na área de psicologia por ser a adoção umas das possibilidades de filiação e estabelecimento de laços familiares de que dispomos (Dolto, 1998; Hamad, 2002; Weber, 2005 e 2007; Maux \& Dutra, 2010; Palacios \& Brodzinsky, 2010; Silva \& Arpini, 2012).

Assim tomando este ponto de partida, falar sobre o tema se converte numa das possibilidades de desconstruir preconceitos que, ao longo da história, foram se formando nesta modalidade de filiação (Weber, 2014), bem como abordar a legislação vigente e as práticas adotadas pelos dois países na consolidação dos laços de filiação por adoção.

\section{Desenvolvimento}

É importante destacar que a adoção não é uma invenção moderna. No século XX, a guerra teria sido uma das maiores causas de abandono de crianças e de adoção (Ijzendoorn \& Juffer, 2006). No Brasil, a história da adoção se fez presente deste a época da colonização, permanecendo muito tempo, numa modalidade de filiação muito silenciada, encoberta por preocupações e desqualificações, tanto no que diz respeito à qualidade da relação de filiação, ainda vivenciada socialmente com sendo de "segunda categoria", quanto pelas problemáticas que frequentemente se associaram aos filhos adotivos, como "filhos problemas" (Paiva, 2004; Levinzon, 2009; Maux \& Dutra, 2010; Silva \& Arpini, 2012). Durante muito tempo, os filhos adotivos ocuparam um lugar diferenciado, sendo tratados de forma muitas vezes discriminatória, não dispondo dos mesmos benefícios que os filhos biológicos. Construiu-se uma trajetória na qual os laços de sangue foram determinantes para se constituir uma relação de filiação (Paiva, 2004; Maux \& Dutra, 2010). Muitos são os temores que circundam a constituição de laços familiares adotivos, no entanto, estudos e pesquisas na área vêm se ocupando deste tema, encarando o desafio de repensar e desconstruir as problemáticas associadas à adoção (Weber, 2014). Embora a experiência da adoção seja uma vivência singular para cada família "existem aspectos comuns que são frequentemente observados como: a relação entre adoção e caridade; adoção e infertilidade; adoção e problemas de aprendizagem; além dos mitos e medos em relação à revelação da adoção para o filho." (Maux e Dutra, 2010, p. 357). Autores como, estudiosos do tema da adoção (Grotevant e McDermott, 2014 e Palácios e Brodzinnky, 2010) têm destacado a importância de mais investigações sobre o tema com enfoque nos aspectos positivos do desenvolvimento, na comunicação em famílias adotivas, entre outros.

\section{Institucionalização e Adoção}

No Brasil, a institucionalização de crianças foi um marco na história, deixando sequelas e consequências nefastas, aspectos que se constituíram em razões suficientes para problematizar sua existência (Rizzini \& Rizzini, 2004). Tais consequências lançaram inúmeros desafios a partir dos anos noventa, as tradicionais instituições vêm passando por mudanças significativas, principalmente quanto aos direitos das crianças e dos adolescentes de terem uma possibilidade de convivência familiar (Brasil, 1990; Rizzini, Rizzini, Naiff \& Baptista, 2006; Arpini, 2016). Dessa forma, ao enfrentar a realidade historicamente tão cronificada dessas instituições, retomando o valor da convivência familiar, a legislação vem buscando reduzir o tempo de institucionalização, evitando que crianças e adolescentes cresçam e se desenvolvam em espaços institucionalizados. Esta nova forma de pensar a relação das crianças nas instituições incide no cenário da adoção.

Em relação a este aspecto, Ijzendoorn e Juffer (2006) têm indicado que crianças que ficam por muito tempo em instituições podem ter prejuízos físicos e psicológicos. Palácios e Brodzinsky (2010) também apontam para as consequências adversas da vida institucional, enfatizando que a institucionalização tem efeitos negativos na vida das crianças. Grotevant e McDermott (2014) apontam que a institucionalização produz efeitos no desenvolvimento cerebral e cognitivo. Assim, segundo os autores quanto menor tempo a criança permanecer na instituição menos efeitos podem decorrer e melhores seriam as possibilidades de seu desenvolvimento. IJzendoorn e Juffer (2006) destacam também que adoções que ocorrem antes dos doze meses de vida do bebê tendem a ser melhores, pois após este período a criança poderia não ter desenvolvido a confiança básica de apego seguro adulto, aspecto tão importante para o desenvolvimento psíquico. Em concordância Grotevant e McDermott (2014) afirmam que a idade da adoção é um elemento importante, uma vez que quanto mais cedo ocorrer me- 
nos efeitos serão sentidos. Em função disso, os autores chamam atenção para a importância de considerar a experiência anterior a adoção, quando avaliados os casos de adoção, pois quanto maiores forem as adversidades vivenciadas e por mais tempo tenham se mantido, mais agravados tendem a ser seus efeitos. Em relação a este aspecto e enfocando estudos e experiências em adoção Palácios e Brodzinsky (2010), referem que adoções que ocorreram após o segundo ano de vida tiveram importantes consequências. Parece importante, no entanto, destacar três aspectos apontados pelos autores: idade, tempo de institucionalização e experiências adversas anteriores a adoção como elementos importantes no processo de avaliação. Os autores destacam que implicações negativas foram identificadas em crianças adotivas que tiveram experiências adversas precocemente e cita entre essas experiências a institucionalização.

O Estatuto da Criança e do Adolescente (Brasil, 1990) considera o acolhimento institucional uma medida de alta complexidade a ser lançada quando outros recursos se mostrarem ineficientes, devendo manter sempre o caráter de excepcionalidade e brevidade. Nesse cenário, a adoção na legislação brasileira atual se constitui numa possibilidade de oferecer às crianças e adolescentes que não podem retornar a suas famílias de origem ou ampliadas, uma experiência familiar, evitando a saída pela via institucional que, como viemos apontando anteriormente, foi por tantos anos uma marca em nossa trajetória (Brasil, 1990, 2009).

Foi somente a partir da Constituição Federal de 1988 (Brasil, 1988) que a lei passou a tratar de forma igualitária todos os filhos, havidos ou não do casamento e por adoção. Logo a seguir, através do Estatuto da Criança e do Adolescente (ECA), uma nova regulamentação da adoção se fez presente no Brasil, tendo o ECA (1990) passado recentemente por alterações por meio da Nova Lei Nacional de Adoção (Brasil, 2009), principalmente em relação aos aspectos que se referem à convivência familiar. Estes se encontram redefinidos e organizados de forma a que o tempo estimado de resolução da problemática familiar seja atendido em um período máximo de dois anos. Com essa normatização tem-se procurado evitar que as crianças fiquem por um período prolongado nas instituições para garantir às crianças e adolescentes uma experiência de vida em um contexto familiar.

Esta nova lei brasileira trouxe para o cenário das instituições de acolhimento um novo olhar sobre a relação com as famílias e a evolução dos casos que ali se encontram, exigindo dos técnicos (psicólogos e assistentes sociais) um novo posicionamento sobre esta realidade e sobre as relações que ali se inscrevem (Arpini 2016; Arpini \& Silva, 2013; Sequeira \& Stella, 2014; Azôr \& Vectore, 2008 ).

No entanto, cabe destacar que críticas têm sido feitas a esta legislação quanto ao fato de que, mais do que valorizar ou tratar da adoção, a ênfase tem sido dada ao retorno à família de origem, ou, em sua impossibilidade, a busca pela família ampliada ou extensa. Tal tem reforçado a concretização dos laços de sangue como sendo aqueles que de fato fazem sentido na trajetória das relações, relegando a adoção para uma opção muito desvalorizada.

Apesar das ponderações que têm sido feitas, devem ser sublinhados alguns aspectos desta legislação, nomeadamente o fato de prever que o tema seja abordado com pais que desejam adotar filhos e que se encontram inscritos nas comarcas brasileiras aguardando a possibilidade da adoção (Brasil, 2009). Destaca-se que, no Brasil, os processos referentes à adoção estão sob a responsabilidade do Juízado da Infância e Adolescência ou do juiz responsável pela comarca, nos municípios que não têm juizado especializado. Nesse sentido, a proposta enfatiza a tese de que não se deve "ensinar pais adotivos a serem pais", mas trabalhar no sentido da desconstrução dos muitos fantasmas que acompanham a história da adoção e que podem se fazer presentes na demanda destes pais (Dolto, 1998). Tal proposta deve, contudo, ser tratada como uma oportunidade e não uma obrigatoriedade, considerando que esta pode não encontrar sentido para alguns pais que buscam adoção. Estas novas ações têm sido importantes para fortalecer a conversa mais aberta sobre o tema. Nessa direção Arpini, Silva e Polli (2010) organizaram um material intitulado Conversando sobre Adoção, com o objetivo de instrumentalizar as pessoas envolvidas com a adoção, em especial os pais trazendo temas como: a construção da filiação adotiva, verdades e mitos sobre a adoção, fantasias presentes nos pais adotivos, o que a criança deve saber sobre a adoção, como falar com a criança e o direito as origens. Destaca-se ainda na realidade brasileira a presença dos Grupos de Apoio a Adoção, os quais trabalham na perspectiva de adoções legais e seguras; pela garantia do direito à família para todas as crianças e adolescentes; pela legitimidade da família adotiva e por uma cultura da adoção. Estima-se que existam mais de cento e vinte grupos em atividade no Brasil segundo a Associação Nacional de Grupos de Apoio a Adoção (www.angaad.org.br). Os trabalhos de Sequeira e Stella (2014) e Silva (2014) evidenciam a importância desses grupos ao trabalharem as relações entre 
pais adotantes e a realidade da filiação adotiva para evitar dificuldades vinculares relacionadas a conteúdos que podem estar mal elaborados e por vezes relacionados à motivação para adoção.

Em Portugal o processo de adoção está a cargo da Segurança Social, assim os candidatos devem se dirigir ao Centro Distrital da Solidariedade e Segurança Social da sua área de residência ou distrito de residência, exceto para os moradores do município de Lisboa, local onde a responsabilidade está a cargo da Santa Casa de Misericórdia. Os candidatos também passam por uma avaliação psicossocial, à semelhança do Brasil (Costa, 2004), porém esta engloba cerca de três entrevistas, sendo que uma delas é realizada na casa dos candidatos. Além das entrevistas, ocorrem pequenos grupos com a participação de seis a oito candidatos como o objetivo de formação parental. Posteriormente, e após a avaliação e seleção pela entidade responsável pelos processos de adoção, inicia-se o período de espera que pode levar anos. Semelhante ao que acontece no Brasil, o tempo de espera se constitui numa das etapas mais difíceis do processo, requerendo paciência e tolerância por parte dos candidatos, para lidar com a incerteza e a angústia dos desdobramentos que se seguirão. Assim, passada esta etapa, e em caso de ter-se encontrado a criança com o perfil desejado, os candidatos podem conhecer a história de vida e r uma foto da criança. Aqui nos parece importante relatar que em Portugal existe um procedimento de preparação para Pré-adoção, do qual participam os técnicos que se encontram nos serviços de adopção e nas instituições de acolhimento. Os técnicos (psicólogos, serviço social, educadores) buscam uma aproximação gradual entre a criança/adolescente e a família adotiva. Esta aproximação começa com um conhecimento à distância entre a criança e a família. Os técnicos da instituição onde a criança está acolhida preparam um "álbum da criança” que é apresentado à família. Também é solicitado à família que elaborem um "álbum da família" que é mostrado à criança. Após esta fase, o primeiro contato tem início na instituição, com um tempo para aproximação entre os adotantes e a criança, e, posteriormente, a família, acompanhada de técnicos do serviço de adoção e da instituição de acolhimento, pode levar a criança para algumas experiências (e.g. atividades de lazer, passeios, refeições) fora da instituição. Somente após estas aproximações é que a criança poderá pernoitar na casa da família adotiva, iniciando-se o período de pré-adopção. O processo é criterioso e sempre acompanhado pelos profissionais. Este acompanhamento dura seis meses e culminará como a elaboração do relatório de Pré-adoção. Pode ainda, durante este período, ser oferecido pelo Serviço de Adoção uma Sessão de Formação Parental com o propósito de apoiar a nova família nas suas funções, auxiliando na consolidação e sustentação dos laços afetivos e das relações familiares.

Assim, pode-se evidenciar que o momento tem oportunizado que aspectos referentes à adoção estejam sendo trabalhados em ambas realidades. Interessante pensar que, embora os procedimentos adotados não sejam semelhantes entre Brasil e Portugal, se pode identificar em ambos uma preocupação com estes laços e com a forma como esta criança ou adolescente será inserida nesta família, que lugar ocupará.

Destaca-se também os aspectos que evidenciam o respeito pela história da criança, as marcas que carrega, assim como a agilidade no processo. Vê-se também uma preocupação com relação aos pais, candidatos à adoção, no sentido de considerar seus "fantasmas" e ajudá-los a não silenciar suas angústias e preocupações. Assim, pode-se entender que os grupos para pais que esperam adoção no Brasil e os grupos de formação parental em Portugal têm a possibilidade de vivenciar uma troca ou compartilhamento de experiências, temores e dúvidas com relação aos aspectos que envolvem a filiação adotiva. Nesse sentido, uma experiência proposta por uma equipe de profissionais de psicologia vinculados à Universidade de Lisboa de oferecer aos pais que têm filhos adotivos um espaço de troca e escuta, parece ampliar a proposta Brasileira com relação aos grupos de pais em espera por adoção.

Em relação a estes aspectos, Palacios e Brodzinsky (2010) ressaltam a importância da aproximação da família adotiva com a realidade da criança, como um tempo em que a família poderá ir adquirindo a segurança em relação a criança e a decisão pela adoção. Destacam ainda, que a comunicação nas famílias adotivas tem sido identificada como um problema para os pais e nesse sentido, é importante a realização de pesquisas e ações que busquem melhor compreender essa questão. As experiências que começam a ser desenvolvidas no Brasil e Portugal parecem caminhar nessa direção.

A preocupação com os pais que estão inscritos aguardando a adoção revela um cuidado com o momento da adoção. A proposta lançada em Portugal permite que os pais possam ter um espaço para partilhar suas experiências de serem pais adotivos, que certamente difere de quando eram, ainda, candidatos a serem pais adotivos. Sabe-se, no entanto, que estas famílias nem sempre estão abertas ou disponíveis para tal encontro, no entanto, o 
que parece ser importante é que existam as oportunidades para que aquelas famílias que desejarem ou necessitarem compartilhar suas singularidades com relação à adoção e os aspectos que envolvem a família adotiva (revelação e diálogo sobre a história de vida da criança, formação do sentido de família, curiosidade pela família de origem, stress parental, rejeição, dificuldades emocionais e comportamentais, coping familiar, entre outros) possam encontrar pares com os quais possam estabelecer essa troca, contando com uma escuta atenta e cuidadosa por parte dos profissionais. Torna-se importante destacar esta iniciativa, assim como os desafios lançados no Brasil e em Portugal acerca do preparo e do momento da adoção, de forma a que, aos poucos, possamos tornar menos silencioso este processo.

Conforme foi destacado, em ambos países tem havido mudanças na legislação e estas têm incidido nas práticas cotidianas, exigindo dos profissionais a superação de preconceitos e estereótipos que se encontram arraigados nessa trajetória. Destaca-se, em especial, a função dos profissionais (direito, psicologia e serviço social), assim como as preocupações referentes aos trâmites que envolvem o processo e que se sabe serem ainda lentos, nem sempre transparentes e, por vezes, engessados.

Palácios e Brodzinsky (2010) referem que o tema tem tido interesse crescente na comunidade acadêmica, com investigações, conferências e encontros. Os autores apontam ainda, para a importância de estudos de caráter interdisciplinar, considerando que o processo de adoção envolve várias áreas do conhecimento. Já Grotevant e McDermott (2014) chamam atenção para a importância de mais pesquisas que foquem nos comportamentos das crianças adotivas, com enfoque também nos aspectos positivos, considerando que a maior parte dos estudos tem abordado os problemas no desenvolvimento decorrentes, como anteriormente citados, de experiências adversas vividas precocemente, abandono, idade da adoção e tempo de institucionalização. Novas demandas também se apresentam a temática decorrentes das mudanças na organização, composição e papéis familiares, entre estas podemos mencionar: adoções por casais homossexuais, adoções transraciais e adoções tardias.

\section{Conclusão}

Em tempos em que tantas transformações estão sendo vivenciadas pela família, existindo uma ampla variedade de modelos e organizações familiares, esta que trata da adoção e da filiação adotiva não poderia nem deveria ficar silenciada. O que se pode destacar neste breve recorte baseado na realidade brasileira e os avanços a partir do ECA e na realidade portuguesa é que o tema está sendo tratado com mais cuidado, valorizando a convivência familiar em detrimento da institucionalização, respeitando os interesses e necessidades das crianças e adolescentes, suas trajetórias e suas origens. São certamente aspectos muito significativos e que retratam importante caminhada, considerando a qualidade das relações que podem ser vivenciadas pela criança na família adotiva, uma vez que podem ser elas próprias terapêuticas para a criança, marcada muitas vezes por histórias prévias frequentemente traumáticas (Ijzendoorn \& Juffer, 2006).

No entanto ainda há muito a fazer, principalmente em relação à agilidade nos processos, desburocratização, bem como o fortalecimento do apoio aos pais e às famílias adotivas. Dessa forma, acreditamos que esta reflexão possa se constituir em mais uma ferramenta a subsidiar a importância das ações voltadas para a adoção, evidenciando iniciativas que podem fortalecer novas ações em ambos os países.

Por fim, destaca-se que os profissionais psicólogos têm ocupado, em ambos os países, um relevante papel nesse processo, razão que chama atenção para a importância de continuamente abrir esse debate nos cursos de formação e pós-graduação em psicologia, através de pesquisas e ações que atualizem e reflitam sobre as mudanças e as especificidades desta construção de laços familiares. Afinal, se há mitos a descontruir eles certamente precisam ser enfrentados no contexto da formação dos psicólogos e daqueles que atuam neste cenário. Isto para evitar que estes profissionais atuem com base em concepções do senso comum, mais do que respaldados pela reflexão e pelo conhecimento acadêmico/científico, a fim de definitivamente se superarem os tantos atravessamentos que se encontram presentes na adoção.

\section{Referências}

Arpini, D. M. (2016). Proteção social de crianças e adolescentes em serviços de acolhimento: Contam-se boas-novas histórias no acolhimento. In: J. de O. Moreira; M. J. G. Salum, \& R. T Oliveira. (orgs.) Estatuto da Criança e do Adolescente: refletindo sobre sujeitos, direitos e responsabilidades. (pp. 120-131). Brasília/DF: CFP.

Arpini, D. M.; Silva, M. L. (2013). O acolhimento institucional na perspectiva da nova Lei Nacional de Adoção. Psicologia Teoria e Prática, 15(3), 95-106.

Arpini, D. M.; Silva, M. L. \& Polli, R. G. (2010). Conversando sobre adoção. Núcleo de Estudos Interdisciplinares em Saúde; Universidade Federal de Santa Maria/ Santa Maria; RS.

Azôr, A. M. G. C. \& Vectore, C. (2008). Abrigar/desabrigar: conhecendo o papel das famílias nesse processo. Estudos de Psicologia, Campinas, 25(1), 77-89. doi: 10.1590/S0103-166X2008000100008

Brasil (1988). Constituição da República Federativa do Brasil. Presidência da República. Brasília/Distrito Federal.

ECA - (1990). Estatuto da Criança e do Adolescente. Lei n.8.069. Brasília, Câmara dos Deputados. 
Brasil (2009). Lei Nacional de Adoção. Lei n. 12.010. Brasília, Câmara dos Deputados.

Costa, L. F. (2004). A subjetividade presente no estudo psicossocial da adoção. Psicologia Reflexão e Crítica. 17(1), 95-104. doi: 10.1590/S010279722004000100012

Dolto, F. (1998). Destinos de crianças: adoção, famílias de acolbimento, trabalho social. São Paulo: Martins Fontes.

Grotevant, H. D. \& McDermott, J. (2014). Adoption: Biological and Social Processes Linked to Adaptation. Revista Psycology, 65, 236-265. doi: 10.1146/ annurev-psych-010213-115020

Hamad, N. (2002). A criança adotiva e suas famílias. Rio de Janeiro; Companhia de Freud.

IJzendoorn, M.H. \& Juffer, F. (2006). Adoption as intervencion, Meta-analytic evidence for massive catch-up and plasticity in physical, socio-emotional, and cognitive development. Journal of child Psychology and Psychiatry, 47(12), 1228-1245.

Levinzon, G. K. (2009). Adoção. São Paulo: Casa do Psicólogo. Coleção clínica psicanalítica.

Maux, A.A.B. \& Dutra, E. (2010). A adoção no Brasil; algumas reflexões. Estudos e Pesquisas em Psicologia, 10 (2), 356-372. doi: 10.12957/epp.2010.8959

Paiva, L. D. (2004). Adoção: significados e possibilidades. São Paulo: Casa do Psicólogo.

Palácios, J. \& Brondzinsky, D. (2010). Adoption Research: Trends, topics, outcomes. International journal of Behavioral Development. 34(3), 270-284. doi: $10.1177 / 0165025410362837$
Rizzini, I.; Rizzini, I. (2004). A institucionalização de crianças no Brasil. Rio de Janeiro: Ed. PUC/RJ.

Rizzini, I.; Rizzini, I; Naiff, L \& Baptista, R (2006). Acolhendo crianças e adolescentes: experiências de promoção do direito a convivência familiar e comunitária no Brasil. São Paulo: Cortez; Brasília: Unicef; Rio de Janeiro: Ciespi Ed. PUC.

Sequeira, V. C. \& Stella, C. (2014). Preparação para a adoçã7o: grupo de apoio para candidatos. Psicologia: teoria e prática, 16 (1), 69-78.

Silva, M. B. T. (2014). Papel dos Grupos de Apoio à Adoção na Garantia do Direito à Convivência Familiar. In: Ladvocat, C., Diuana, S. (orgs). Guia de Adoção no Jurídico, no Social, no Psicológico e na Família. São Paulo: Editora Roca, $1^{\text {a }}$ edição.

Silva, M. L. \& Arpini, D. M. (2012). Fortificando laços e desatando nós: a adoção ao longo da história. In: D. M. Arpini \& A. C. Siqueira, (org.) Psicologia, Famílias e Leis: desafios a realidade brasileira (pp.45-70). Santa Maria: Ed. UFSM.

Weber, L. N. D. (2005) O psicólogo e as práticas de adoção. In: H. S. Gonçalves, \& E. P. Brandão, (Orgs.). Psicologia Jurídica no Brasil (pp. 99-140). Rio de Janeiro: Nau.

, (Org.) (2007). Filhos adotivos, pais adotados: depoimentos e histórias de escolhas. Curitiba: Gráfica Capital.

, (2014). Aspectos Psicológicos da adoção. Curitiba: Editora Juruá, 2a edição, $9^{\mathrm{a}}$ reimpressão.

Submetido em: 27-7-2017

Aceito em: 28-6-2018 